ORIGINAL ARTICLE

\title{
Role of colonoscopic biopsy in distinguishing between Crohn's disease and intestinal tuberculosis
}

\author{
R Kirsch, M Pentecost, P de M Hall, D P Epstein, G Watermeyer, P W Friederich
}

J Clin Pathol 2006;59:840-844. doi: 10.1136/icp.2005.032383

See end of article for authors' affiliations .....................

Correspondence to: R Kirsch, Department of Pathology, Mount Sinai Hospital, 600 University Arenue, Toronto, ON M5G 1X5, Canada; rkirsch@mtsinai.on.ca

Accepted for publication 1 February 2006

\begin{abstract}
Background: The histological differential diagnosis of Crohn's disease and intestinal tuberculosis can be very challenging, as both are chronic granulomatous disorders with overlapping histological features.

Aim: To evaluate selected clinical and histological parameters in colonic biopsy specimens for their ability to discriminate between Crohn's disease and intestinal tuberculosis.

Methods: 25 patients with Crohn's disease and 18 patients with intestinal tuberculosis were selected for this study on the basis of established clinical, radiological and histological criteria. Clinical data and selected histological parameters in colonoscopic biopsy specimens were assessed retrospectively. A total of 103 and 41 biopsy sites were evaluated in patients with Crohn's disease and intestinal tuberculosis, respectively.

Results: Clinical parameters helpful in differentiating intestinal tuberculosis from Crohn's disease included chest radiographic features of tuberculosis $(56 \% \vee 0 \%)$, perianal fistulae $(0 \% \vee 40 \%)$ and extraintestinal manifestations of Crohn's disease (0\% v 40\%). Histopathological features that seemed to reliably differentiate between intestinal tuberculosis and Crohn's disease included confluent granulomas, $\geqslant 10$ granulomas per biopsy site and caseous necrosis (in biopsy samples of 50\%,33\% and $22 \%$ of patients with intestinal tuberculosis, respectively, $v 0 \%$ of patients with Crohn's disease). Features that were observed more often in patients with intestinal tuberculosis than in those with Crohn's disease included granulomas exceeding $0.05 \mathrm{~mm}^{2}(67 \% \vee 8 \%)$, ulcers lined by conglomerate epithelioid histiocytes $(61 \% \vee 8 \%)$ and disproportionate submucosal inflammation $(67 \%$ v $10 \%)$.

Conclusion: Clinical features and selected histological parameters in colonoscopic biopsy specimens can help in differentiating between Crohn's disease and intestinal tuberculosis.
\end{abstract}

$\mathrm{D}$ ifferentiating between intestinal tuberculosis and Crohn's disease can be a major diagnostic challenge, particularly in developing countries where intestinal tuberculosis remains common. ${ }^{1-5}$ Several clinical studies and case reports highlight the difficulties in making this distinction. ${ }^{6-12}$ This distinction is important as treatment for these two conditions differs considerably. ${ }^{7}{ }^{13}$ Both intestinal tuberculosis and Crohn's disease are chronic granulomatous conditions and show an overlap in their histological features. ${ }^{14-16}$ In addition, the diagnostic features of tuberculosis (acid-fast bacilli and caseous necrosis) are infrequently observed in colonoscopic biopsy specimens. ${ }^{17-21}$ Whereas the recent literature is dominated by case reports from countries not endemic for these diseases, ${ }^{6} 7911$ recent attempts have been made to identify additional histological features with discriminatory value. ${ }^{14}{ }^{16}$ Studies from southern India, where tuberculosis is endemic, have found colonoscopic biopsy specimens from patients with intestinal tuberculosis to be characterised by multiple, large and confluent granulomas, disproportionate submucosal inflammation and ulcers lined by "conglomerate epithelioid histiocytes". ${ }^{14} 16$ These features were absent or infrequent in biopsy specimens from patients with Crohn's disease. ${ }^{14} 16$ In addition, topographical differences in the distribution of granulomas in patients with Crohn's disease and intestinal tuberculosis have recently been shown. ${ }^{16}$ By contrast, a study from western China found that most colonoscopic biopsy specimens from patients with intestinal tuberculosis were indistinguishable from those of patients with Crohn's disease..$^{15}$ Given these conflicting reports, we evaluated the relative frequencies of selected histological parameters in a population of patients with intestinal tuberculosis and of those with Crohn's disease from Cape Town, South Africa, where both conditions are common..$^{22-25}$

\section{PATIENTS AND METHODS}

The Ethics Committee of the Faculty of Health Sciences, University of Cape Town, South Africa, approved this study. In this retrospective study, the databases of the Departments of Anatomical Pathology and Gastroenterology, Groote Schuur Hospital, Cape Town, were reviewed to identify patients with Crohn's disease or those with intestinal tuberculosis diagnosed between 1984 and 2004. This included a review of a clinical database of patients with confirmed Crohn's disease and of the pathology files at Groote Schuur Hospital. The pathology files at Groote Schuur Hospital were searched using SNOMED codes for the following terms: "Crohn's disease", "granulomatous inflammation", "nonnecrotizing granulomatous inflammation", "necrotizing granulomatous inflammation", "tuberculosis" and "acid fast-bacilli". The initial search identified 164 patients with Crohn's disease and 52 with intestinal tuberculosis. A further review was conducted to identify those patients who underwent biopsy before definitive treatment was started and to ensure that the diagnosis of either intestinal tuberculosis or Crohn's disease was based on established clinical, radiological, histological and microbiological parameters. The diagnosis of intestinal tuberculosis was based on (1) demonstration of acid-fast bacilli in histological sections $(\mathrm{n}=12)$; (2) culture of Mycobacterium tuberculosis from colonic biopsy specimens $(n=2)$; (3) positive sputum culture and prompt response to antituberculous treatment $(n=2)$; or $(4)$ strong suspicion of tuberculosis on both clinical and histological grounds, together with a prompt response to antituberculous treatment $(n=2)$. All 18 patients with intestinal tuberculosis and 25 consecutive patients with Crohn's disease who met the selection criteria were included in the study. Five patients with Crohn's disease and five with 
Table 1 Endoscopic localisation of disease in patients with Crohn's disease and those with intestinal tuberculosis, in whom colonoscopic data were available

\begin{tabular}{llll}
\hline $\begin{array}{l}\text { Endoscopic } \\
\text { localisation }\end{array}$ & $\begin{array}{l}\text { Crohn's } \\
\text { disease, } \\
\mathbf{n}(\%)\end{array}$ & $\begin{array}{l}\text { Intestinal } \\
\text { tuberculosis, } \\
\mathbf{n}(\%)\end{array}$ & $\mathbf{p}$ Value \\
\hline Pancolitis & $7(28)$ & $2(11)$ & 0.169 \\
lleocaecal & $7(28)$ & $3(17)$ & 0.342 \\
Right-sided & $2(8)$ & $4(22)$ & 0.189 \\
Transverse & $0(0)$ & $3(17)$ & 0.117 \\
Left-sided & $7(28)$ & $3(17)$ & 0.342 \\
Rectal & $2(8)$ & $2(11)$ & 0.562 \\
\hline
\end{tabular}

intestinal tuberculosis had undergone testing for HIV and all were found to be HIV negative. With the exception of one patient with Crohn's disease who had terminal ileal disease (accessible to biopsy), all patients with Crohn's disease and those with intestinal tuberculosis had colonic involvement. Colonoscopy was carried out under sedation, with an Olympus fibreoptic or video colonoscope (Olympus, Hamburg, Germany), after appropriate bowel preparation. In both groups, biopsy specimens were taken from normal and abnormal sites in the colon and terminal ileum. In the group with Crohn's disease, 103 sites were sampled (76 abnormal, 27 normal; average 2.7 biopsies per site). In the group with intestinal tuberculosis, 41 sites were sampled (28 abnormal, 13 normal; average 4 biopsies per site). Biopsy specimens were fixed in buffered formaldehyde, embedded in paraffin wax and serially sectioned at $5 \mu \mathrm{m}$ and stained with haematoxylin and eosin. In both groups, an average of four sections was present on each slide. Slides stained with haematoxylin and eosin were examined by a pathologist (RK) using coded slides to avoid observer bias. Granulomas were defined as localised collections of epithelioid histiocytes with or without Langerhans giant cells. ${ }^{14}{ }^{16}$ In each specimen, granulomas were characterised with respect to number, size, location and the presence or absence of confluence and caseous necrosis. Conglomerate bands of epithelioid histiocytes lining ulcers or ulcer slough ${ }^{14}{ }^{16}$ and disproportionate submucosal inflammation were recorded when present.
Disproportionate submucosal inflammation was defined as submucosal inflammation exceeding that of the overlying non-ulcerated mucosa, ${ }^{14}$ and was only assessed in biopsy specimens containing submucosa $(20$ specimens from 10 patients with Crohn's disease and 11 specimens from 9 patients with intestinal tuberculosis). In all specimens, the presence or absence of acute inflammation (cryptitis, crypt abscess or ulceration with acute inflammation), chronic inflammation and architectural distortion was recorded. The $\chi^{2}$ test and Fischer's exact probability test were used to evaluate differences in the frequency of the various histological parameters. The Mann-Whitney $U$ test was used for comparison of medians.

\section{RESULTS}

Clinical and endoscopic findings

The mean age at diagnosis was 32.1 (SD 15) and 35 (9.5) years and the male:female ratio was 2:3 and 2:1 in patients with Crohn's disease and in those with intestinal tuberculosis, respectively. With regard to race, among the patients with Crohn's disease, 23 were of mixed ancestry, 2 were black and none were white, whereas among the patients with tuberculosis, 11 were of mixed ancestry, 5 were black and 2 were white. In all, 13 (52\%) patients with Crohn's disease had documented evidence of perianal disease compared with $1(6 \%)$ patient with intestinal tuberculosis $(p=0.004)$. Of these, $10(40 \%)$ patients with Crohn's disease had perianal fistulae compared with none of those with intestinal tuberculosis $(\mathrm{p}=0.002)$. In patients undergoing chest radiography, 10 of $18(56 \%)$ patients with intestinal tuberculosis had features suggestive of pulmonary tuberculosis compared with none of the 14 patients with Crohn's disease $(p=0.00002)$. Of the 25 patients with Crohn's disease, $12(40 \%)$ had extraintestinal manifestations, including arthritis $(n=3)$, arthralgia $(n=5)$, ankylosing spondylitis $(n=1)$ and erythema nodosum $(n=2)$. None of these manifestations were documented in patients with intestinal tuberculosis. Minor differences were seen in the distribution of the endoscopic lesions in patients with Crohn's disease and those with intestinal tuberculosis, but these did not reach statistical significance (table 1).

Table 2 Prevalence of selected histological parameters in patients with IT and CD

\begin{tabular}{|c|c|c|c|c|c|c|c|c|c|c|c|c|}
\hline \multirow[b]{2}{*}{$\begin{array}{l}\text { Histopathological } \\
\text { parameters }\end{array}$} & \multicolumn{3}{|c|}{ All patients } & \multicolumn{3}{|c|}{ All biopsy specimens } & \multicolumn{3}{|c|}{$\begin{array}{l}\text { Endoscopically abnormal } \\
\text { mucosa }\end{array}$} & \multicolumn{3}{|c|}{$\begin{array}{l}\text { Endoscopically normal } \\
\text { mucosa }\end{array}$} \\
\hline & $\begin{array}{l}\text { IT } \\
(n=18)\end{array}$ & $\begin{array}{l}C D \\
(n=25)\end{array}$ & p Value & $\begin{array}{l}\text { IT } \\
(n=41)\end{array}$ & $\begin{array}{l}C D \\
(n=103)\end{array}$ & p Value & $\begin{array}{l}\text { IT } \\
(n=28)\end{array}$ & $\begin{array}{l}C D \\
(n=77)\end{array}$ & p Value & $\begin{array}{l}\text { IT } \\
(n=13)\end{array}$ & $\begin{array}{l}C D \\
(n=26)\end{array}$ & p Value \\
\hline Granulomas & $78 \%$ & $28 \%$ & $0.0035^{*}$ & $46 \%$ & $14 \%$ & $0^{*}$ & $56 \%$ & $16 \%$ & $0^{*}$ & $7 \%$ & $7 \%$ & 0.7 \\
\hline $\begin{array}{l}\text { Average number of } \\
\text { granulomas }\end{array}$ & 6.5 & 2.5 & 0.054 & 2.85 & 0.6 & $0.0007^{*}$ & 4.11 & 0.7 & $0^{*}$ & 0.15 & 0.3 & 0.988 \\
\hline $\begin{array}{l}\text { Granulomas } \geqslant 5 \text { per } \\
\text { biopsy site }\end{array}$ & $44 \%$ & $24 \%$ & 0.28 & $20 \%$ & $7 \%$ & $0.029^{*}$ & $29 \%$ & $8 \%$ & $0.01^{*}$ & 0 & 0 & - \\
\hline $\begin{array}{l}\text { Granulomas } \geqslant 10 \text { per } \\
\text { biopsy site }\end{array}$ & $33 \%$ & 0 & $0.003^{*}$ & $15 \%$ & 0 & $0.0005^{*}$ & $21 \%$ & 0 & $0.0003^{*}$ & 0 & 0 & - \\
\hline Granulomas $>0.05 \mathrm{~mm}^{2}$ & $67 \%$ & $8 \%$ & $0.0002^{*}$ & $31 \%$ & $2 \%$ & 0 * & $46 \%$ & $2 \%$ & $0^{*}$ & 0 & 0 & - \\
\hline Confluent granulomas & $50 \%$ & 0 & $0^{*}$ & $24 \%$ & 0 & $0^{*}$ & $36 \%$ & 0 & $0^{*}$ & 0 & 0 & - \\
\hline Caseous necrosis & $22 \%$ & 0 & $0.025^{*}$ & $10 \%$ & 0 & $0.006^{*}$ & $14 \%$ & 0 & $0.004^{*}$ & 0 & 0 & - \\
\hline Mucosal granulomas & $44 \%$ & $40 \%$ & 0.4 & $22 \%$ & $13 \%$ & 0.25 & - & - & & - & - & - \\
\hline Submucosal granulomas & $44 \%$ & $12 \%$ & $0.02^{*}$ & $22 \%$ & $4 \%$ & $0.002^{*}$ & - & - & & - & - & - \\
\hline $\begin{array}{l}\text { Granulation tissue } \\
\text { granulomas }\end{array}$ & $26 \%$ & $8 \%$ & 0.16 & $10 \%$ & $2 \%$ & $0.052^{*}$ & - & - & & - & - & - \\
\hline $\begin{array}{l}\text { Ulcer with epithelioid } \\
\text { histiocytes }\end{array}$ & $61 \%$ & $8 \%$ & $0.0002^{*}$ & $30 \%$ & $2 \%$ & $0^{*}$ & $39 \%$ & $3 \%$ & $0^{*}$ & 0 & 0 & - \\
\hline $\begin{array}{l}\text { Disproportionate } \\
\text { submucosal chronic } \\
\text { inflammation }\end{array}$ & $67 \%$ & $10 \%$ & $0.02^{*}$ & $55 \%$ & $5 \%$ & $0.004^{*}$ & $60 \%$ & $7 \%$ & $0.007^{*}$ & 0 & 0 & - \\
\hline
\end{tabular}



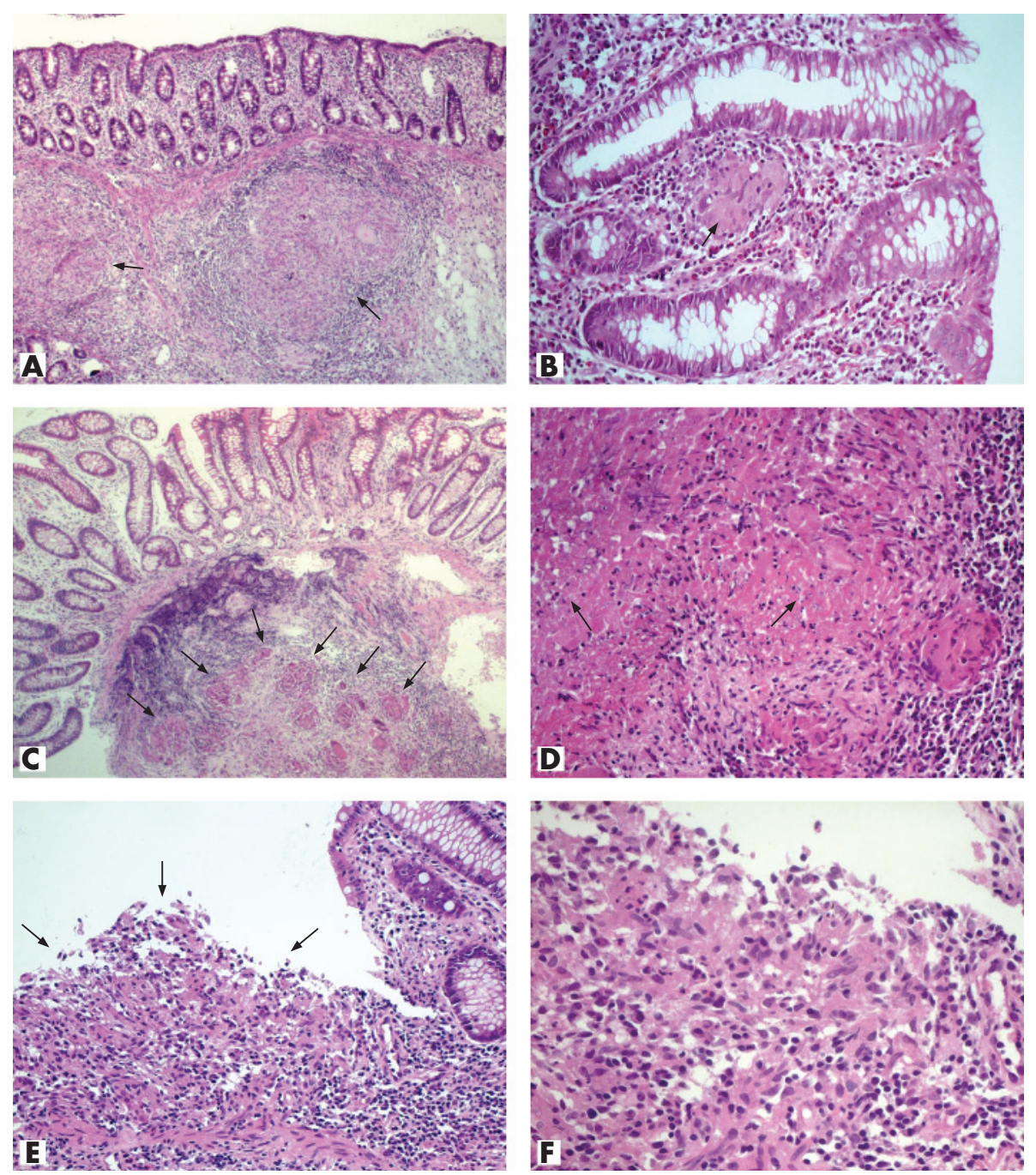

Figure 1 Colonic biopsy specimens from patients with disease, stained with haematoxylin and eosin (H\&E). (A) A patient with intestinal tuberculosis showing large submucosal granulomas (arrows), magnification $4 \times$. (B) A patient with Crohn's disease showing a solitary, small mucosal granuloma (arrow), magnification $20 \times$. (C) A patient with intestinal tuberculosis showing multiple submucocal granulomas (arrows), magnification $4 \times$. (D) A patient with intestinal tuberculosis showing confluent granulomas with caseous necrosis (arrows), magnification $10 \times$. (E) A patient with intestinal tuberculosis showing a conglomerate band of epithelioid histiocytes in an area of ulceration (arrows), magnification 10x. (F) High-magnification micrograph of a conglomerate band of epithelioid histiocytes lining an ulcer in a patient with intestinal tuberculosis, H\&E, magnification $20 \times$.

\section{Histopathological findings}

Table 2 shows selected histopathological parameters in patients with intestinal tuberculosis and Crohn's disease. Granulomas were present in the biopsy specimens of $78 \%$ of patients with intestinal tuberculosis and in $28 \%$ of those with Crohn's disease $(\mathrm{p}=0.001)$. An average of 2.85 granulomas per biopsy site were present in patients with intestinal tuberculosis compared with 0.6 granulomas per biopsy site in those with Crohn's disease $(p=0.0007)$. We found that $44 \%$ of patients with intestinal tuberculosis had biopsy specimens containing $\geqslant 5$ granulomas compared with $24 \%$ of patients with Crohn's disease $(\mathrm{p}=0.28)$. Biopsy specimens containing $\geqslant 10$ granulomas were present in $33 \%$ of patients with intestinal tuberculosis but in none of the patients with Crohn's disease $(p=0.003)$. Large granulomas were commonly seen in biopsy specimens from patients with intestinal tuberculosis (fig 1A) but were uncommon in specimens from patients with Crohn's disease in whom granulomas were typically small (fig $1 \mathrm{~B}$ ). In all, 67\% of patients with intestinal tuberculosis had biopsy specimens containing granulomas exceeding $0.05 \mathrm{~mm}^{2}$ in size (an area corresponding to a single quadrant of $1 \mathrm{HPF}, 40 \times$ objective (field area $0.2 \mathrm{~mm}^{2}$ )) compared with $8 \%$ of patients with Crohn's disease $(\mathrm{p}=0.002)$.

Granulomas predominated in the submucosa in patients with intestinal tuberculosis compared with a predominantly mucosal location in those with Crohn's disease

(submucosa:mucosa granuloma ratio 3.2 v 1:3; fig $1 \mathrm{~A}-\mathrm{C}$ ). Submucosal granulomas were present in biopsy specimens from $44 \%$ of patients with intestinal tuberculosis compared with $12 \%$ of those with Crohn's disease $(p=0.02)$. Confluent granulomas were seen in biopsy specimens from $50 \%$ of patients with intestinal tuberculosis (fig 1D) but were not observed in specimens from patients with Crohn's disease $(p=0.00009)$. Caseous necrosis was identified in biopsy specimens from $22 \%$ of patients with intestinal tuberculosis (fig 1D) compared with none of patients with Crohn's disease $(p=0.025)$. Bands of conglomerate epithelioid histiocytes in ulcers or ulcer slough (fig $\mathrm{lE}, \mathrm{F}$ ) were a frequent finding in biopsy specimens from patients with intestinal tuberculosis but were infrequent in specimens from those with Crohn's disease $(61 \% \vee 8 \% ; p=0.0002)$. The evaluation of biopsy specimens in which submucosa was present showed disproportionate submucosal chronic inflammation in $67 \%$ of 
patients with intestinal tuberculosis (fig $1 \mathrm{C}$ ) and in only $10 \%$ of those with Crohn's disease $(\mathrm{p}=0.02)$.

Features that were present in the biopsy specimens of most patients with intestinal tuberculosis and those with Crohn's disease, and were therefore not discriminatory, included acute inflammation (cryptitis, crypt abscesses or acutely inflamed ulcer; $89 \%$ v 92\%), chronic inflammation (mucosal or submucosal; $100 \% \vee 100 \%$ ) and architectural distortion (crypt branching; 100\% $v 100 \%$ ).

\section{DISCUSSION}

Tuberculosis is a major health problem in South Africa. In Cape Town almost 23000 new cases of tuberculosis were registered in 2003 (an incidence of 678 per 100000 people), many in association with HIV infection. ${ }^{24}$ Inflammatory bowel disease is less common, with an incidence of 1.6 per $100000 .{ }^{25}$ Differentiating between intestinal tuberculosis and Crohn's disease often poses a major diagnostic challenge in this setting. Currently, little literature is available on the role of colonoscopic biopsy in differentiating between intestinal tuberculosis and Crohn's disease. Numerous studies have documented the histopathology of intestinal tuberculosis $^{19}{ }^{21} 26-28$ and Crohn's disease, ${ }^{18}{ }^{29-32}$ but relatively few have compared the histopathological features of these two conditions, ${ }^{14-16} 18212733$ the latter mostly in resection specimens. Two studies by Pulimood et al ${ }^{14}{ }^{16}$ have evaluated several histological parameters in a southern Indian population of patients with intestinal tuberculosis and Crohn's disease and suggested a role for colonoscopic biopsy in distinguishing between these two conditions. Until now, there have been no similar studies from other regions of the world where tuberculosis is endemic. Our findings, in a South African population of patients, support those of Pulimood et al. Features that reliably distinguished patients with intestinal tuberculosis from those with Crohn's disease in our study included confluent granulomas, $\geqslant 10$ granulomas per biopsy site and caseous necrosis, which were present in biopsy specimens from $50 \%, 33 \%$ and $22 \%$ of patients with intestinal tuberculosis, respectively, compared with none of the patients with Crohn's disease. Features that were far more frequent in patients with intestinal tuberculosis than in those with Crohn's disease included granulomas exceeding $0.05 \mathrm{~mm}^{2}$ in size $(67 \% \vee 8 \%)$, ulcers lined by bands of epithelioid histiocytes (61\% $v 8 \%)$, disproportionate submucosal inflammation ( $67 \%$ v 10\%) and submucosal granulomas $(47 \% v 12 \%)$. Our findings differ from those of Gan et al, ${ }_{1}^{15}$ who found colonoscopic biopsy specimens to be unhelpful in differentiating between intestinal tuberculosis and Crohn's disease. Their study, however, evaluated only a small number of histopathological parameters (caseous necrosis, confluent granulomas, ulceration, lymphoid aggregates and chronic inflammation), the major focus being PCR assay for $M$ tuberculosis DNA. ${ }^{15}$

As expected, several clinical parameters were useful in differentiating intestinal tuberculosis from Crohn's disease. These included chest radiographic features of tuberculosis (56\% $v 0 \%)$, perianal fistulae $(0 \% \vee 40 \%)$ and extraintestinal manifestations of Crohn's disease ( $0 \% v 40 \%)$. Although data are limited by small sample size and the retrospective nature of this study, they do highlight the diagnostic usefulness of extraintestinal manifestations in intestinal tuberculosis and Crohn's disease. In South Africa, Crohn's disease has historically been a disease primarily affecting white people, whereas tuberculosis has affected mostly black people and people of mixed race. This distinction has become less clear as South African society has changed, particularly over the last 15 years. Our cohort of patients with intestinal tuberculosis and with Crohn's disease was not clearly divided along racial lines. Most patients were of mixed race in both groups. The

\section{Take-home messages}

- Intestinal tuberculosis may mimic Crohn's disease clinically, endoscopically and histologically.

- Intestinal tuberculosis should be considered in the differential diagnosis of Crohn's disease, particularly in regions where tuberculosis is endemic.

- Colonoscopic mucosal biopsy specimens may be of value in differentiating between intestinal tuberculosis and Crohn's disease.

- In addition to caseous necrosis and acid-fast bacilli (which are present in a minority of biopsy specimens from patients with intestinal tuberculosis), size, number and confluence of granulomas, presence of ulcers lined by bands of epithelioid histiocytes and disproportionate submucosal inflammation may help in differentiating intestinal tuberculosis from Crohn's disease.

- Larger, prospective studies may help in identifying combinations of histological and clinical features with a positive predictive value for intestinal tuberculosis sufficient to merit a trial of antituberculous treatment.

group of patients with Crohn's disease included two black patients, whereas the group with intestinal tuberculosis included two white patients, highlighting the limitations of race in distinguishing between these two conditions.

Novel diagnostic modalities may supplement current methods for distinguishing between intestinal tuberculosis and Crohn's disease. Both serology $y^{34}$ and PCR $^{15} 35$ have shown promise in this regard. Available data, however, comes from small studies from a few centres and remain to be validated in larger studies. Moreover, the value of serology and PCR for $M$ tuberculosis remains to be determined in endemic regions where the rate of subclinical infection with tuberculosis is high. It therefore remains a priority to identify histological features, in colonoscopic biopsy specimens, that may help in differentiating intestinal tuberculosis and Crohn's disease. Although individual histological features may lack the sensitivity or specificity for definitive diagnosis of intestinal tuberculosis, the presence of several features may prompt the clinician to investigate more rigorously for tuberculosis. Moreover, it may be possible through larger, prospective studies to identify combinations of histological and clinical features with a positive predictive value for intestinal tuberculosis, which would be sufficient to merit a trial of antituberculous treatment. Finally, a subset of patients with intestinal tuberculosis and of those with Crohn's disease will lack discriminatory features in endoscopic biopsy specimens. Management of these patients, as always, is guided by clinical, endoscopic and radiologic findings, maintaining a high index of suspicion for both conditions, particularly in regions where both Crohn's disease and intestinal tuberculosis are common.

\section{ACKNOWLEDGEMENTS}

We thank Dr David Metz and Dr Robert Riddell for their advice on the manuscript and Dr Sedick Isaacs for help with the statistical analysis.

\author{
Authors' affiliations \\ R Kirsch, M Pentecost, P de M Hall, Department of Anatomical \\ Pathology, Faculty of Health Sciences, University of Cape Town, Cape \\ Town, South Africa \\ D P Epstein, G Watermeyer, P W Friederich, Department of \\ Gastroenterology, Faculty of Health Sciences
}


Competing interests: RK was the recipient of a post-doctoral research fellowship from the Faculty of Health Sciences, University of Cape Town, Cape Town, South Africa. PWF was supported by a research grant from AstraZeneca BV, The Netherlands.

\section{REFERENCES}

1 Jayanthi V, Robinson RJ, Malathi S, et al. Does Crohn's disease need differentiation from tuberculosis? J Gastroenterol Hepatol 1996; 11:183-6.

2 Kapoor VK. Koch's or Crohn's: the debate continues. Int J Clin Pract 1997;51:532.

3 Kapoor VK. Koch's or Crohn's? Int J Clin Pract 1997;51:246-7.

4 Green J, Davies S, Currie C, et al. Koch's or Crohn's-or something else? Int J Clin Pract 1997:51:480

5 Aston NO. Abdominal tuberculosis. World J Surg 1997;21:492-9.

6 Arnold C, Moradpour D, Blum HE. Tuberculous colitis mimicking Crohn's disease. Am J Gastroenterol 1998;93:2294-6.

7 Wagner TE, Huseby ES, Huseby JS. Exacerbation of mycobacterium tuberculosis enteritis masquerading as Crohn's disease after treatment with a tumor necrosis factor-alpha inhibitor. Am J Med 2002;1 12:67-9.

8 Kaushik SP, Bassett ML, McDonald C, et al. Case report: gastrointestinal tuberculosis simulating Crohn's disease. J Gastroenterol Hepatol 1996;11:532-4.

9 Petroianni A, Mugnaini L, Laurendi G, et al. Abdominal tuberculosis mimicking Crohn's disease: a difficult diagnosis. Report of a case. Panminerva Med 2002:44:155-8.

10 Lau CF, Wong AM, Yee KS, et al. A case of colonic tuberculosis mimicking Crohn's disease. Hong Kong Med J 1998;4:63-6.

11 Chatzicostas C, Koutroubakis IE, Tzardi M, et al. Colonic tuberculosis mimicking Crohn's disease: case report. BMC Gastroenterol 2002;2:10.

12 Isbister WH, Hubler M. Inflammatory bowel disease in Saudi Arabia: presentation and initial management. J Gastroenterol Hepatol 1998; 13:1119-24

13 Arend SM, Breedveld FC, van Dissel JT. TNF-alpha blockade and tuberculosis: better look before you leap. Neth J Med 2003:61:111-9.

14 Pulimood AB, Ramakrishna BS, Kurian G, et al. Endoscopic mucosal biopsies are useful in distinguishing granulomatous colitis due to Crohn's disease from tuberculosis. Gut 1999;45:537-41.

15 Gan HT, Chen YQ, Ouyang Q, et al. Differentiation between intestinal tuberculosis and Crohn's disease in endoscopic biopsy specimens by polymerase chain reaction. Am J Gastroenterol 2002;97:1446-51.

16 Pulimood AB, Peter S, Ramakrishna BS, et al. Segmental colonoscopic biopsies in the differentiation of ileocolic tuberculosis from Crohn's disease. J Gastroenterol and Hepatol 2005;20:688-96.
17 Shepherd NA. Pathological mimics of chronic inflammatory bowel disease. J Clin Pathol 1991;44:726-33.

18 Lee FD, Roy AD. Ileo-caecal granulomata. Gut 1964;19:517-23.

19 Howell JS, Knapton PJ. Ileo-caecal tuberculosis. Gut 1964;19:524-9.

20 Gilinsky NH, Marks IN, Kottler RE, et al. Abdominal tuberculosis. A 10-year review. S Afr Med J 1983;64:849-57.

21 Tandon HD, Prakash A. Pathology of intestinal tuberculosis and its distinction from Crohn's disease. Gut 1972;13:260-9.

22 World Health Organization. Global tuberculosis control: surveillance, planning, financing, WHO report number WHO/HTM/TB/2005.349 Geneva: WHO, 2005: 126-8.

23 Wright JP, Marks IN, Jameson C, et al. Inflammatory bowel disease in Cape Town, 1975-1980. Part II. Crohn's disease. S Afr Med J 1983:63:226-9.

24 Cape Town TB Control. A partnership between the provincial administration of the Western Cape metropole region and the City of Cape Town. Progress Report 1997-2003. http://hst.org.za/uploads/files/tb_ct.pdf (accessed 10 May 2006).

25 Wright JP, Froggatt J, O'Keefe EA, et al. The epidemiology of inflammatory bowel disease in Cape Town 1980-1984. S Afr Med J 1986:70:10-5.

26 Franklin GO, Mohapatra M, Perrillo RP. Colonic tuberculosis diagnosed by colonoscopic biopsy. Gastroenterology 1979;76:362-4.

27 Hoon JR, Dockerty MB, Pemberton J. Ileocecal tuberculosis including a comparison of this disease with nonspecific regional enterocolitis and noncaseous tuberculated enterocolitis. Int Abstr Surg 1950;91:417-40.

28 Palmer KR, Patil DH, Basran GS, et al. Abdominal tuberculosis in urban Britain-a common disease. Gut 1985;26:1296-305.

29 Morson BC. Pathology of inflammatory bowel disease. Gastroenterol Japan 1980;15:184-7.

30 Chambers TJ, Morson BC. The granuloma in Crohn's disease. Gut 1979;20:269-74.

31 Williams WJ. Histology of Crohn's syndrome. Gut 1964;19:510-6.

32 Cook MG, Dixon MF. An analysis of the reliability of detection and diagnostic value of various pathological features in Crohn's disease and ulcerative colitis. Gut 1973;14:255-62.

33 Liu TH, Pan GZ, Chen MZ. Crohn's disease. Clinicopathologic manifestations and differential diagnosis from enterocolonic tuberculosis. Chin Med J (Engl) $1981 ; 94: 431-40$.

34 Kashima K, Oka S, Tabata A, et al. Detection of anti-cord factor antibodies in intestinal tuberculosis for its differential diagnosis from Crohn's disease and ulcerative colitis. Dig Dis Sci 1995;40:2630-4.

35 Gan $\mathrm{H}$, Ouyang $\mathrm{Q}, \mathrm{Bu} \mathrm{H}$, et al. Value of polymerase chain reaction assay in diagnosis of intestinal tuberculosis and differentiation from Crohn's disease. Chin Med J (Engl) 1995;108:215-20.

36 Anand BS, Schneider FE, El-Zaatari FA, et al. Diagnosis of intestinal tuberculosis by polymerase chain reaction on endoscopic biopsy specimens. Am J Gastroenterol 1994;89:2248-9. 